\title{
Interlaboratory Calibrations and Methodological Comparisons for the Re-Os Isotope System
}

\author{
D. HNATYSHIN ${ }^{1}$, D. VAN ACKEN ${ }^{2}$, R.A. CREASER ${ }^{3}$, J. \\ TOMA $^{3}$, S. JOHNSON ${ }^{1}$, M. W. HITZMAN ${ }^{1}$
}

${ }^{1}$ Irish Centre for Research in Applied Geoscience, University College Dublin, Dublin, Ireland (*danny.hnatyshin@ icrag-centre.org, murray.hitzman@icrag-centre.org, sean.johnson@icrag-centre.org)

${ }^{2}$ School of Earth Sciences, University College Dublin, Dublin, Ireland (david.vanacken@ucd.ie)

${ }^{3}$ Department of Earth \& Atmospheric Sciences, University of Alberta, Edmonton, AB, Canada (rcreaser@ualberta.ca, toma@ualberta.ca)

The Re-Os isotope system has shown wide applicability in many fields of Earth Science (e.g. economic geology, chronostratigraphy, mantle geochemistry, environmental tracing), therefore making it an attractive isotope system to pursue for many geochemistry laboratories.

To facilitate the development of a world-class Re-Os lab at University College Dublin (UCD) an interlaboratory collaboration between researchers at UCD, the Irish Centre for Research in Applied Geosciences (iCRAG), and the ReOs Crustal Geochronology Lab at the University of Alberta (UofA) was undertaken. Specifically, we demonstrate that the mixed ${ }^{185} \mathrm{Re}^{190} \mathrm{Os}$ spike developed for UCD is well calibrated, and that the analytical instruments chosen for isotope analysis (i.e. TIMS, MC-ICP-MS) have been properly scrutinized.

The mixed ${ }^{185} \mathrm{Re}^{190} \mathrm{Os}$ spike solution created for UCD was calibrated at UCD to $4.403+/-0.002 \mathrm{pmol} / \mathrm{g}$, and 3.051 $+/-0.030 \mathrm{nmol} / \mathrm{g}$, for ${ }^{190} \mathrm{Os}$ and ${ }^{185} \mathrm{Re}$ respectively. Crosscalibration at the UofA produced values within error of the UCD calibrations $(4.392+/-0.028 \mathrm{pmol} / \mathrm{g}$, and $3.072+/-$ $0.007 \mathrm{nmol} / \mathrm{g}$, for ${ }^{190} \mathrm{Os}$ an ${ }^{185} \mathrm{Re}$, respectively). These calibrations are then checked against two well-defined shale isochrons $(191.18+/-0.94 \mathrm{Ma}, \mathrm{MSWD}=0.52 ; 192.0+/-1.4$ Ma, MSWD =1.4) from [1] and the SBC-1 shale standard.

To determine if there is any difference in methodological choice for Re measurements, Re solutions were split into two separate cuts prior to analysis, one for analysis using TIMS at the UofA, and the other for MC-ICP-MS analysis at UCD. The resulting analyses show repeatability of $\sim 0.2 \%$ between these two analytical methods, a important consideration when performing high-precision analyses.

[1] Toma, 2019, Re-Os Chronostratigraphy of the Lower Jurassic Fernie Formation, unpublished MSc Thesis, University of Alberta. 